\title{
ANATOMIA DO XILEMA SECUNDÁRIO DE Mimosa uruguensis Hook. et Arn.
}

José Newton Cardoso Marchiori

Departamento de Ciências Florestais - Centro de Ciências Rurais UFSM - Santa Maria, RS

\section{RESUMO}

O objetivo do presente trabalho é a descrição anatômica da madeira de Mimosa uruguensis Hook. et Arn. (Leguminosae Mimosoideae). São fornecidas fotomicrografias e dados quantitativos de detalhes anatômicos.

A estrutura anatômica é especializada e típica para a familia Leguminosae. Entre seus aspectos mais importantes incluem-se: pontuações ornamentadas em vasos, raios compostos inteiramente de células procumbentes e poros em múltiplos racemiformes, tendendo ao arranjo dendrítico.

A estrutura anatômica é comparada com referências da literatura sobre a família Leguminosae e gênero Mimosa, em uma análise taxonômica e filogenética.

Palavras Chave: Anatomia da Madeira, Leguminosae, Mimosoideae, Mimosa uruguensis.

\section{SUMMARY}

MARCHIORI, J.N.C. Anatomy of the Secondary Xylem of Mimosa uruguensis Hook. et Arn. Ciência e Natura, Santa Maria,

This paper describes the wood anatomy of Mimosa uruguensis Hook et Arn. (Leguminosae Mimosoideae). Photomicrographs and quantitative data of its anatomical structure are also furnished.

The anatomical structure is specialized and typical to the Leguminosae. Vestured pits in vessel members, rays composed by only 
procumbent cells and pores in clusters, tending to a dendritic pattern, are the most important features of this wood.

The anatomical structure is compared with literature on the Leguminosae family and Mimosa L. genus, in a taxonomical and phylogenetical analysis.

KEYWORDS: Wood Anatomy, Leguminosae, Mimosoideae, Mimosa uruguensis.

\section{INTRODUÇÃO}

O gênero Mimosa L. compreende mais de 400 espécies no continente americano, distribuídas desde o sul dos Estados Unidos até o Uruguai e centro da Argentina. Na África e Ásia, são escassas as espécies nativas.

A taxonomia das Mimosas, estabelecida por BENTHAM (1875), está fundamentada na morfologia floral. As espécies são distribuídas nas secções Habbasia e Eumimosa, distinguidas entre si por terem flores diplostêmones e isostêmones, respectivamente. Cada uma das referidas secções agrupa diversas séries botânicas.

A espécie descrita no presente trabalho, é um arbusto de até $3 \mathrm{~m}$ de altura, glabro, muito ramificado, provido de ramos avermelhados e acúleos retos, dispersos. As folhas apresentam um par de estipulas oval-lanceoladas, medem até $2 \mathrm{~cm}$ de comprimento e compreendem de 1 a 3 pares de pinas. Na base de cada raquis pinar encontra-se um par de estipelas orbiculares ou cordiformes, de até $1 \mathrm{~mm}$ de comprimento. Os folíolos, em número de 5 a 13 pares por pina, são oblongos, obtusos e muito aproximados. As flores são rosadas, dispondo-se em capítulos axilares com pedúnculos de 1 a $4 \mathrm{~cm}$ de comprimento. Apresentam corola com 3 ou 4 lóbulos e seis ou oito estames, respectivamente. O fruto é um Iomento linear-comprimido, glabro, inerme, escuro, reto ou subfalcado e finamente glanduloso; mede de 1 a $4,5 \mathrm{~cm}$ de comprimento por 5-6 $\mathrm{mm}$ de largura, tendo replo persistente e 1 a $€$ artículos (BURKART, 1987).

Mimosa uruguensis Hook. et Arn. inclui-se na secção Habbasia Benth., por suas flores diplostêmones. A presença de estipelas orbiculares ou 
A área de ocorrência de Mimosa uruguensis restringe-se à bacia do rio Uruguai, incluindo as províncias argentinas de Corrientes e Entre Rios, a República do Uruguai (BURKART, 1987) e região oeste do Rio Grande do Sul. É interessante observar-se que RAMBO (1966) não incluiu a espécie em seu estudo sobre as leguminosas rio-grandenses, e que a mesma também não figura na Flora de Santa Catarina, de acordo com BURKART (1979).

Para a área de ocorrência natural de Mimosa uruguensis são citadas outras 5 espécies nativas, pertencentes à mesma secção Habbasia e série Stipellares: Mimosa amphigena Burk., Mimosa cruenta Benth., Mimosa hassleriana Chod., Mimosa trachycarpa Benth. (LOMBARDO, 1964) e Mimosa ostenii Speg. (BURKART, 1987).

A estrutura anatômica do xilema secundário foi muito pouco investigado no gênero Mimosa, devido ao limitado interesse econômico, da maioria de suas espécies.

COZZO (1951), em estudo de 11 espécies argentinas, observou uma grande variação anatômica, não reconhecendo um traço comum ao grupo. Neste estudo foram incluidas 4 espécies da série Stipellares: Mimosa uruguensis, Mirnosa ostenii, Mimosa hassleriana e Mimosa cruenta.

Para Mimosa uruguensis foram referidos a predominância de poros agrupados e raios unisseriados, compostos de células horizontais. A presença de poros em múltiplos agregados, foi também referida para as outras 3 espécies examinadas, pertencentes à série Stipellares (COZZO, 1951).

Para Mimosa cruenta, MARCHIORI (1985) destacou a presença de uma porosidade dendrítica, sugerindo que o caráter possa ter valor taxonômico para o reconhecimento da série Stipellares. Foram também referidos poros muito pequenos e extremamente numerosos, elementos vasculares muito curtos, placas de perfuração simples, espessamentos espiralados tênues em vasos, parênquima axial abundante, raios fracamente heterogêneos, fibras libriformes e ausência de estratificação.

O presente trabalho visa descrever os aspectos anatômicos da madeira de Mimosa uruguensis e comparar sua estrutura com referências da literatura para o gênero Mimosa e família Leguminosae 


\section{MATERIAL E MÉTODOS}

O material estudado é procedente do Estado do Rio Grande do Sul. Consiste de 8 amostras de madeira, conservadas no Herbário e Xiloteca do Departamento de Ciências Florestais (HDCF), com os seguintes registros:

- HDCF 578. Itaqui, RS, arredores da cidade. Marchiori, J.N.C., 25/11/1981;

- HDCF 697. Loreto, São Vicente do Sul, RS. Marchiori, J.N.C., 17/9/1982;

- HDCF 715. Alegrete, RS, restinga do rio Ibirapuitã. Marchiori, J.N.C., 30/9/1982;

- HDCF 716. Alegrete, RS, arredores da cidade. Marchiori, J.N.C., 30/9/1982;

- HDCF 718. Alegrete, RS, BR 290 (Km 528). Marchiori, J.N.C. , 30/9/1982;

- HDCF 720. Barra do Quaraí, RS. Marchiori, J.N.C., 01/10/1982;

- HDCF 721. Barra do Quaraí, RS. Marchiori, J.N.C., 01/10/1982;

- HDCF 722. Barra do Quaraí, RS, barranca do rio Quaraí. Marchiori, J.N.C., $01 / 10 / 82$.

De cada amostra de madeira foram preparados 3 corpos de prova, orientados para a obtenção de cortes anatômicos nos planos transversal, longitudinal radial e longitudinal tangencial, respectivamente. Os corpos de prova foram amolecidos por fervura em água e seccionados em micrótomo de deslizamento, regulado para uma espessura nominal de $18 \mu \mathrm{m}$.

Os cortes anatômicos foram coloridos com Acridina-vermelha, Crisoidina e Azul-de-astra (DUJARDIN, 1964), desidratados em série alcoólica e montados em lâminas permanentes. Usou-se Entellan, como meio de montagem.

Para a confecção de lâminas de macerado, usou-se solução de Jeffrey (FREUND, 1970), coloração com safranina e o mesmo meio de montagem anteriormente referido.

A terminologia adotada, as medições e descrição da estrutura anatômica, seguiram as recomendações da COPANT (1973). Para a determinação da percentagem dos diferentes tipos celulares, seguiu-se a metodologia recomendada por MARCHIORI (1980. B). Os dados quantitativos e determinações estereológicas são apresentados na Tabela 1.

As fotomicrografias foram tomadas em microscópio ótico, marca Carl Zeiss, no Laboratório de Anatomia da Madeira, da Universidade Federal do Paraná. 


\section{DESCRIÇÃO DA MADEIRA}

Vasos: Muito numerosos, ocupando $24,7 \%$ da secção transversal da madeira (Figuras 1.A,B; 3.A). Porosidade em anéis semi-porosos, havendo a formação de uma faixa de poros de maior diâmetro, no início do anel de crescimento (Figura 1.A,B). Poros de diâmetro pequeno $(47-79-113 \mu \mathrm{m}) \mathrm{e}$ secção oval, dispostos em múltiplos racemiformes, com tendência ao arranjo dendrítico (Figura 1.A-C; 2.A). Elementos vasculares muito curtos (107 - 154 - 223 $\mu \mathrm{m})$, com placas de perfuração simples, com espessamentos espiralados e apêndices ausentes, ou então curtos (7,5 - $25-65 \mu \mathrm{m})$, em apenas uma das extremidades.

Pontoado intervascular alterno. Pontoações de forma poligonal a oval, pequenas (5,5 - 6,4 - $8 \mu \mathrm{m})$, ornamentadas e com abertura lenticular-inclusa.

Pontoações raio-vasculares pequenas $(3,5-4,5-5,5 \mu \mathrm{m}) \mathrm{e}$ arredondadas (Figura 2.B,C). Pontoações parênquimo-vasculares de muito pequenas a pequenas $(3,5-4,2-4,5 \mu \mathrm{m})$, semelhantes às raio-vasculares.

Parênquima axial: Pouco abundante, em disposição paratraqueal (Figura 1.C; 2.A) e ocupando cerca de $10,2 \%$ do volume da madeira. As células parenquimáticas normalmente não envolvem todo o contorno dos múltiplos racemiformes, sendo freqüente o contato entre vasos e fibras. A coalescência do parênquima axial entre os grupos racemiformes de poros, contribui para o reconhecimento do padrão dendrítico.

Séries de parênquima axial de 205 - 259 - $330 \mu \mathrm{m}$ de altura por 10 15 - $21 \mu \mathrm{m}$ de largura, compostas invariavelmente de apenas 2 células. Células fusiformes ligeiramente mais curtas e estreitas, com 187 - 235 - $285 \mu \mathrm{m}$ de altura e 7 - 13 - $19 \mu \mathrm{m}$ de largura.

$\mathrm{Na}$ periferia do parênquima paratraqueal observam-se séries cristaliferas em contato com as fibras, compostas por 13-27 câmaras (Figura 2.D) e contendo monocristais rombóides.

Raios: Muito numerosos (9 - 12 - 15 raios $/ \mathrm{mm}$ ), compondo cerca de $12,5 \%$ do volume da maueira. Raios de relacionamento normal (Figuras 2.D; 3.CE), mas não raro fusionados axialmente; raios agregados, ausentes. Tecido radial homogêneo, composto apenas de células procumbentes (Figura 2.B,C) e secção curto-ovalada em plano tangencial (Figura 2.D). 
Raios unisseriados representando $18,7 \%$ do total; muito baixos (25 122 - $290 \mu \mathrm{m})$, extremamente finos $(7,5-11-18 \mu \mathrm{m})$ e com 1 - 10 - 24 células de altura (Figuras 2.D; 3.C,E).

Raios multisseriados, em sua maioria bisseriados $(47,3 \%)$, menos comumente trisseriados $(33,5 \%)$ e raramente tetrasseriados $(0,5 \%)$; desde baixos a medianos (100 - $308-683 \mu \mathrm{m})$, muito finos (14 - 22 - $35 \mu \mathrm{m})$, e com 10 - 25 - 54 células de altura (Figuras 2.D; 3.C,E).

Células eretas, quadradas, latericuliformes, envolventes, mucilaginosas, oleíferas, esclerosadas e cristalíferas, ausentes no tecido radial.

Fibras: Tecido fibroso proeminente, representando mais de $50 \%$ do volume da madeira. Fibras libriformes, não septadas, freqüentemente gelatinosas e com diminutas pontoações simples, mais abundantes na face radial da parede celular.

Fibras muito curtas $(430-531-700 \mu \mathrm{m})$, estreitas $(8,7-13-18 \mu \mathrm{m}) \mathrm{e}$ de paredes delgadas a espessas $(1,2-2,3-3,1 \mu \mathrm{m})$.

Outros caracteres: Anéis de crescimento distintos, marcados por um estreito lenho tardio, com fibras de diâmetro radial ligeiramente menor e pela concentração de poros em estreita faixa, no início do anel seguinte. Canais secretores, tubos laticiferos e taniníferos, líber incluso e estratificação, ausentes

\section{DISCUSSÃO}

Os principais aspectos anatômicos da madeira de Mimosa uruguensis, tais como elementos vasculares muito curtos, placas de perfuração simples, pontoações alternas, parênquima paratraqueal, raios homogêneos e fibras libriformes, tem ocorrência generalizada na família Leguminosae, de acordo com METCALFE \& CHALK, 1972 e RECORD \& HESS, 1949, e atestam um alto grau de especialização ao xilema secundário.

A presença de pontoações ornamentadas, observada na madeira em estudo, é interpretada por BARETTA-KUIPERS (1981) como uma das características mais constantes e peculiares na estrutura anatômica das Leguminosae. 

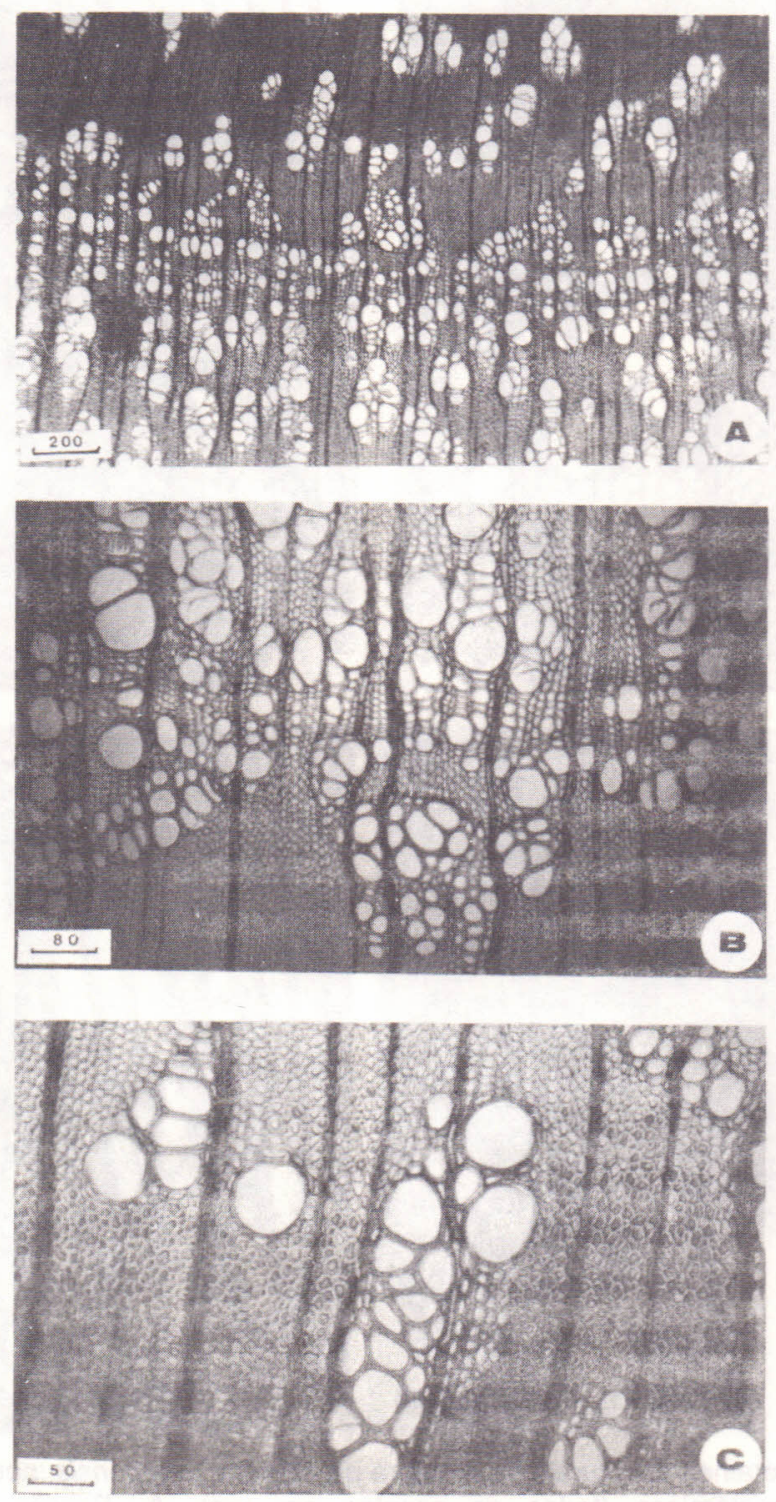

FIGURA 1. Aspectos da secção transversal da madeira de Mimosa uruguensis (todas as escalas em $\mu \mathrm{m}$ ). A. Detalhe de um limite de anel de crescimento, mostrando a porosidade em anéis semi-porosos e poros em múltiplós racemiformes, tendentes ao arranjo dendritico. $B$. Mesmos aspectos da fotomicrografia anterior, embora com maior aumento. C. Parênquima paratraqueal e poros ovalados, em múlt plos racemiformes. 

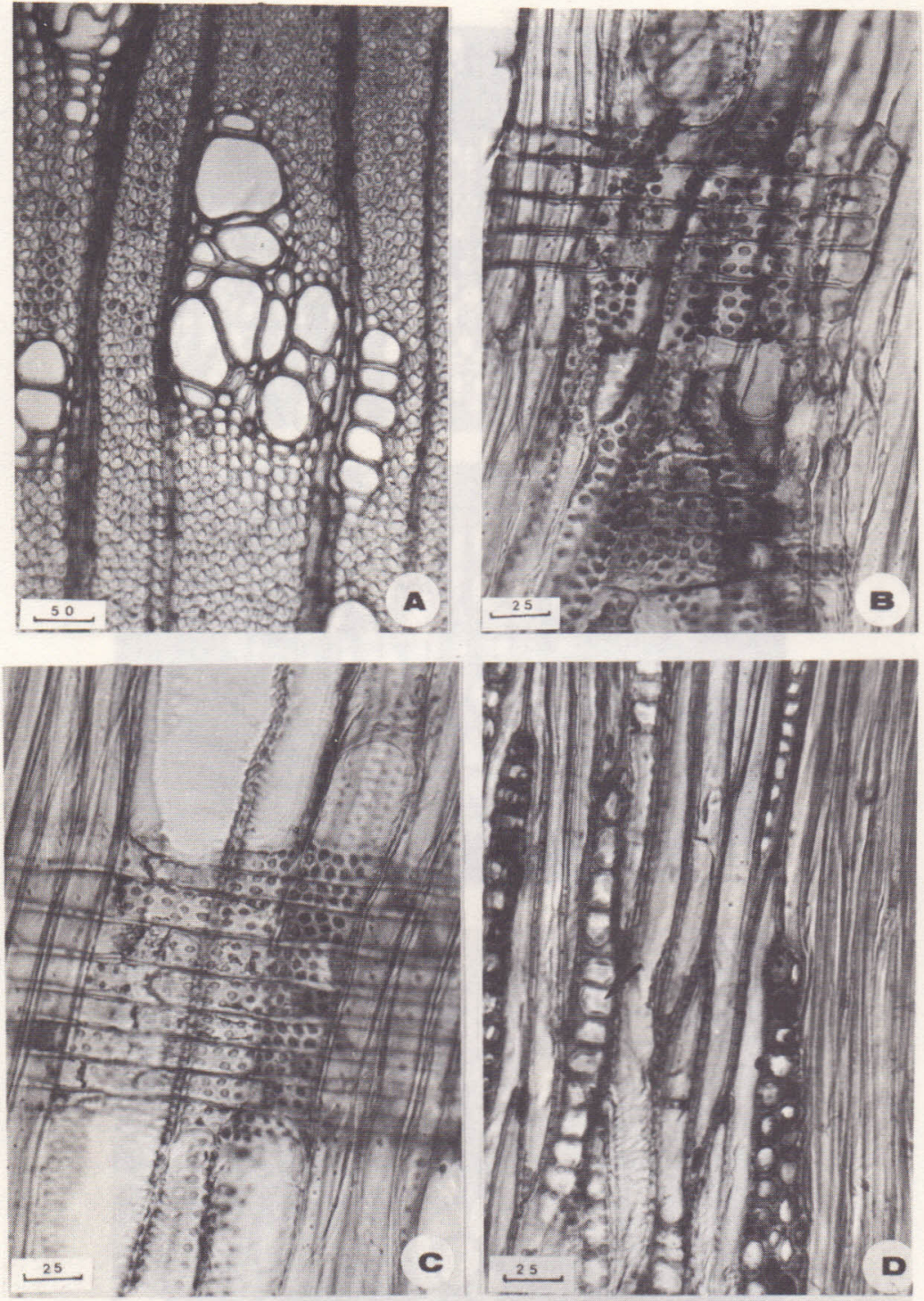

Figura 2. Detalhes estruturais da madeira de Mimosa uruguensis, nos três planos anatômicos (todas as escalas em $\mu \mathrm{m}$ ). A. Secção transversal, mostrando o parênquima axial associado a um agrupamento racemiforme ae poros. B. Secção longitudinal radial, destacando um raio homogêneo e pontoações raio-vasculares. C. Detalhe de raio homogêneo e pontoações raio-vasculares. D. Secção longitudinal tangencial, mostrando raios unisseriados e multisseriados com células de contorno oval, parênquima paratraqueal e uma série cristalífera de 13 câmaras (seta). 

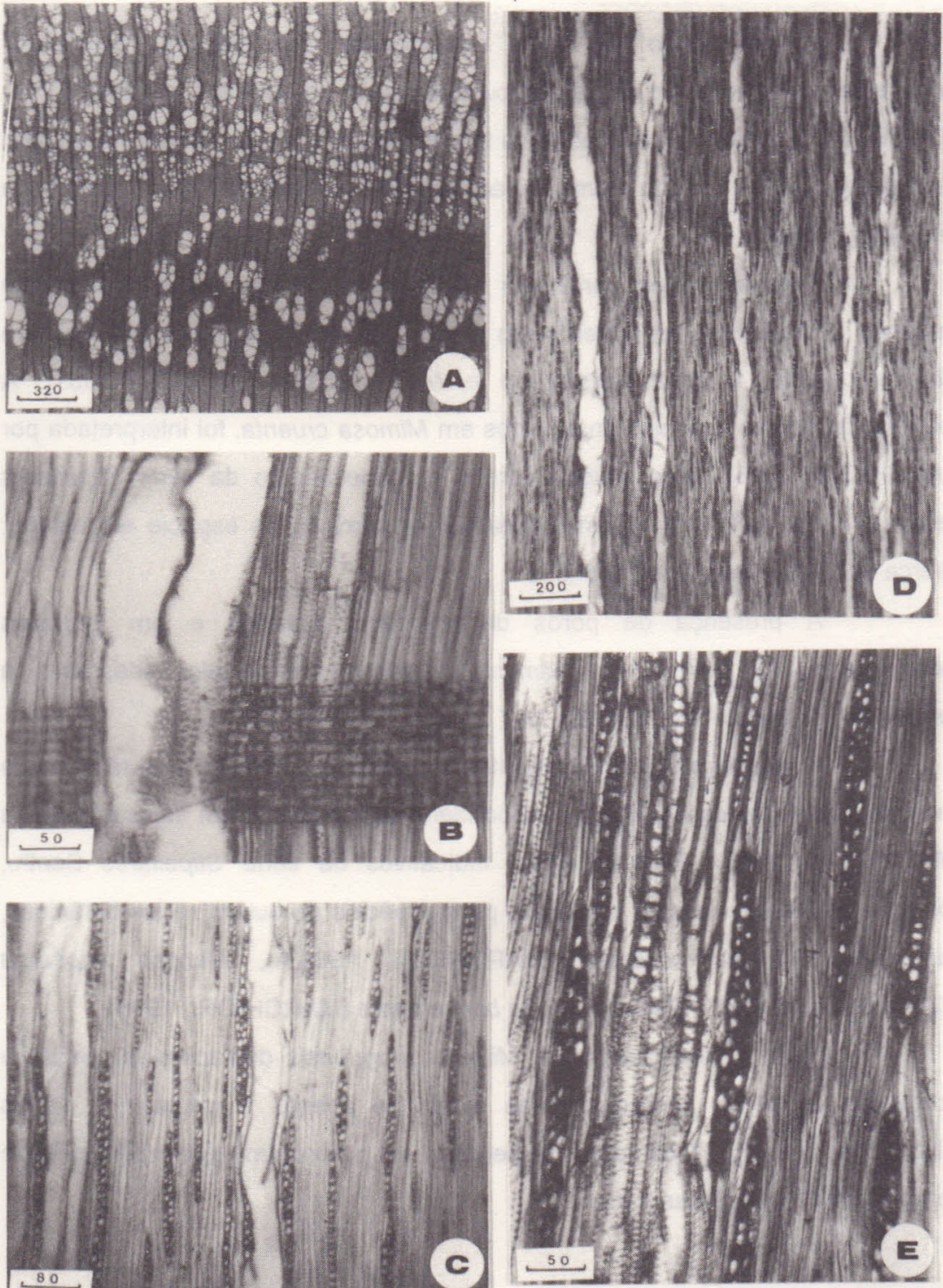

Figura 3. Aspectos anatômicos da madeira de Mimosa uruguensis (todas as escalas em $\mu \mathrm{m})$. A. Secção transversal, mostrando o arranjo característico dos poros. B. Secção longitudinal radial, destacando um raio homogêneo. C. Secção longitudinal tangencial, mostrando raios unisseriados e multisseriados, de relacionamento normal. D. Linhas vasculares e raios muito finos, em secção longitudinal tangencial. E. Detalhe da secção longitudinal tangencial, destacando séries cristalíferas no parênquima axial e raios muito finos. 
A observação de raios homogêneos em Mimosa uruguensis, compostos inteiramente de células procumbentes, é considerada por BARETTAKUIPERS (1981) como uma importante tendência evolutiva no xilema secundário das Mimosoideae, quando comparadas à relativamente primitiva sub-família Caesalpinioideae.

A presença de poros em múltiplos racemiformes e em arranjo tendendo a dendrítico, no material em estudo, foram também registradas em Mimosa cruenta, Mimosa hassleriana e Mimosa ostenii (COZZO, 1951). A confirmação destes aspectos anatômicos em Mimosa cruenta, foi interpretada por MARCHIORI (1985) como valiosa para o reconhecimento da série Stipellares Benth. A observação dos mesmos detalhes anatômicos na espécie em estudo, reforça esta interpretação taxonômica.

A presença de poros de diâmetro pequeno e em múltiplos racemiformes, na madeira de Mimosa uruguensis, tem valor adaptativo à xeromorfia, de acordo com CARLQUIST (1975).

A presença de espessamentos espiralados em vasos e de raios muito finos, raramente tetrasseriados, correspondem ao observado em Mimosa cruenta (MARCHIORI, 1985). Este aspectos, indicativos da série Stipellares Benth., contrastam nitidamente com o descrito para espécies de outras séries botânicas, tais como Mimosa scabrella (MARCHIORI, 1980.A), Mimosa eriocarpa (CARNIELETTO et al., 1993) e Mimosa bimucronata (MARCHIORI, 1993).

Para a identificação de Mimosa uruguensis destacam-se, ainda, a ocorrência de séries parenquimáticas axiais de apenas 2 células, de séries cristalíferas com 15-27 câmaras na periferia do parênquima paratraqueal e de fibras muito curtas, não septadas.

\section{CONCLUSŌES}

A estrutura anatômica da madeira de Mimosa uruguensis permite a formulação das seguintes conclusões:

- A madeira apresenta uma estrutura anatômica evoluída, à semelhança das demais espécies da família Leguminosae; 
- A ocorrência de pontoações ornamentadas é característica da familia Leguminosae;

- A presença de raios homogêneos, compostos inteiramente de células horizontais, testemunha a posição evoluída do xilema das Mimosoideae, quando comparadas à relativamente primitiva sub-família Caesalpinioideae;

- A presença de poros em múltiplos racemiformes e arranjo dendrítico são indicativos da série Stipellares Benth., dentro do gênero Mimosa L.;

- A ocorrência de raios muito finos e espessamentos espiralados em vasos, são sugestivos da série Stipellares Benth., mas requerem confirmação, mediante estudo mais abrangente deste grupo de espécies;

- A presença de poros muito pequenos e agrupados, tem valor adaptativo à xeromorfia.

\section{REFERÊNCIAS BIBLIOGRÁFICAS}

BARETTA-KUIPERS, T. Wood Anatomy of Leguminosae: its relevance to Taxonomy. In: POLHILL, R.M., RAVEN, P.H. Advances in Legume Systematics. Kew, Ministery of Agriculture, Fisheries and Food, 1981. p. 677715.

BENTHAM, G. Revision of the suborder Mimoseae. Transact. Linnean Society of London, v. 30, p. 335-664, 1875.

BURKART, A. Leguminosas Mimosoideas. In: REITZ, P.R. Flora llustrada Catarinense. Itajai, 1979. 299 p.

BURKART, A. Leguminosae. In: BURKART, A. Flora llustrada de Entre Rios (Argentina). Buenos Aires: Coleccion Cientifica del INTA, 1987. v. 6, p. 442738.

CARLQUIST, S. Ecological Strategies of Xylem Evolution. Berkeley: University of California Press, 1975. 259 p.

CARNIELETTO, C., MAKCHIORI, J.N.C. Anatomia da madeira de Mimosa eriocarpa Benth. Ciência Florestal, v. 3, n. 1, p. 107-120, 1993.

COPANT - COMISSÃO PANAMERICANA DE NORMAS TÉCNICAS. Descrição macroscópica, microscópica e geral da madeira - esquema I de recomendação. Colômbia, 1973. 19 p. (COPANT 30). 
COZZO, D. Anatomia del Leño Secundario de las Leguminosas Mimosoideas y Caesalpinioideas Argentinas Silvestres y Cultivadas. Revista del Instituto Nacional de Investigacion de las Ciencias Naturales, Buenos Aires, v. 2, n. 2, p. 63-146, 1951

DUJARDIN, E.P. Eine neue holzellulosenfaerbung. Mikrokosmos, n. 53, p. 94 , 1964.

FREUND, H. Handbuch der Mikroskopie in der Technik. Frankfurt: Umsham Verlag, 1970. 375 p.

LOMBARDO, A. Flora Arborea y Arborescente del Uruguay. Montevideo: Concejo Departamental, 1964. $151 \mathrm{p}$.

MARCHIORI, J.N.C. Estudo Anatômico do Xilema Secundário e da Casca de algumas espécies dos gêneros Acacia e Mimosa, nativas no Estado do Rio Grande do Sul. Curitiba, 1980.A. 186f. Dissertação. Mestrado. Curso de Pós-Graduação em Engenharia Florestal. Setor de Ciências Agrárias. Universidade Federal do Parana.

MARCHIORI, J.N.C. Comprovação da viabilidade de utilização da secção longitudinal tangencial para a determinação histométrica dos elementos axiais do xilema secundário. In: CONGRESSO FLORESTAL ESTADUAL, IV. Anais do... Nova Prata, 1980.B. p. 180-184.

MARCHIORI, J.N.C. Anatomia da madeira de Mimosa cruenta Benth. (Leguminosae Mimosoideae). Ciência e Natura, Santa Maria, v. 7, p. 73-81, 1985.

MARCHIORI, J.N.C. Anatomia da madeira e casca do maricá, Mimosa bimucronata (DC.) O. Ktze. Ciência Florestal, Santa Maria, v. 3, n. 1, p. 85106, 1993.

METCALFE, C.R., CHALK, L. Anatomy of the Dicotyledons. Oxford: Clarendon Press, 1972. $1500 \mathrm{p}$.

RAMBO, B. Leguminosae Riograndenses. Pesquisas, Série Botânica, n. 23, p. 1166,1966

RECORD, S.J., HESS, R.W. Timbers of the New World. New Haven: Yale University Press, 1949. 640 p. 
TABELA 1. Dados quantitativos e determinações estereológicas da madeira de Mimosa uruguensis.

\begin{tabular}{|c|c|c|c|c|}
\hline CARACTERISTICA & $\begin{array}{l}\text { VALOR } \\
\text { MÍNIMO }\end{array}$ & MÉDIA & $\begin{array}{l}\text { VALOR } \\
\text { MÁXIMO }\end{array}$ & $\begin{array}{l}\text { DESVIO } \\
\text { PADRÃO }\end{array}$ \\
\hline 1. Fração de poros (\%) & 17,0 & 24,7 & 29,0 & 4,85 \\
\hline 2. Diâmetro tangencial de poros $(\mu \mathrm{m})$ & 47,0 & 79,0 & 113,0 & 16,36 \\
\hline 3. Comprimento elementos vasculares $(\mu \mathrm{m})$ & 107,0 & 159,0 & 223,0 & 30,49 \\
\hline 4. Comprimento de apêndices $(\mu \mathrm{m})$ & 7,5 & 25,0 & 65,0 & 13,97 \\
\hline 5. Diâmetro pontoações intervasculares $(\mu \mathrm{m})$ & 5,5 & 6,4 & 8,0 & 0,66 \\
\hline 6. Diâmetro pontoaçöes raio-vasculares $(\mu \mathrm{m})$ & 3,5 & 4,5 & 5,5 & 0,77 \\
\hline 7. Diâm. pont. parênquimo-vasculares $(\mu \mathrm{m})$ & 3,5 & 4,2 & 4,5 & 0,35 \\
\hline 8. Fração parênquima axial (\%) & 6,0 & 10,2 & 13,0 & 2,63 \\
\hline 9. Altura séries parênquima axial $(\mu \mathrm{m})$ & 205,0 & 259,0 & 330,0 & 29,89 \\
\hline 10. Largura séries parênquima axial $(\mu \mathrm{m})$ & 10,0 & 15,0 & 21,0 & 2,46 \\
\hline 11. Altura células fusiformes $(\mu \mathrm{m})$ & 187,0 & 235,0 & 285,0 & 27,09 \\
\hline 12. Largura células fusiformes ( $\mu \mathrm{m})$ & 7,0 & 13,0 & 19,0 & 2,77 \\
\hline 13. Fração tecido radial (\%) & 9,0 & 12,5 & 15,0 & 2,25 \\
\hline 14. Freqüência de & 9,0 & 12,0 & 15,0 & 1,65 \\
\hline 15. Fração raios uniss & 16,0 & 18,7 & 22,0 & 1,96 \\
\hline 16. Altura raios unisse & 25,0 & 122,0 & 290,0 & 61,97 \\
\hline 17. Altura raios unisseriados (células) & 1 & 10 & 24 & 5,24 \\
\hline 18. Largura raios unisseriados $(\mu \mathrm{m})$ & 7,5 & 11,0 & 18,0 & 2,01 \\
\hline 19. Fração raios bisseriados (\%) & 43 & 47,3 & 52 & 3,26 \\
\hline 20. Fração raios trisseriados (\%) & 28,0 & 33,5 & 38,0 & 3,72 \\
\hline 21. Fração raios tetrasseriados (\%) & - & 0,5 & 1,0 & 0,54 \\
\hline 22. Altura raios multisseriados $(\mu \mathrm{m})$ & 100,0 & 308,0 & 683,0 & 127,55 \\
\hline 23. Altura raios multisseriados (células) & 10 & 25 & 54 & 10,48 \\
\hline 24. Largura raios multisseriados $(\mu \mathrm{m})$ & 14,0 & 22,0 & 35,0 & 5,77 \\
\hline 25. Largura raios multisseriados (células & 2 & 2,5 & 4 & 0,56 \\
\hline 26. Fração de fibras (\%) & 45,0 & 52,6 & 59,0 & 5,53 \\
\hline 27. Comprimento de fibras $(\mu \mathrm{m})$ & 430,0 & 531,0 & 700,0 & 69,86 \\
\hline 28. Diâmetro de fibras $(\mu \mathrm{m})$ & 8,7 & 13,0 & 17,5 & 1,89 \\
\hline 29. Diâmetro lume de fibras ( & 5,0 & 9,3 & 12,5 & 2,14 \\
\hline 30. Espessura parede de fibras $(\mu \mathrm{m})$ & 1,2 & 2,3 & 3,1 & 0,53 \\
\hline
\end{tabular}





\section{ERRATA}

Onde se lê "Mimosa urugunesis Hook. et Arn. inclui-se na secção Habbasia Benth., por suas flores diplostêmones. A presença de estipelas orbiculares ou", leia-se "Mimosa urugunesis Hook. et Arn. inclui-se na secção Habbasia Benth., por suas flores diplostêmones. A presença de estipelas orbiculares ou cordiformes na base das pinas foliares, indica sua inserção na série Stipellares Benth.", na página 104. 